\title{
Molecular and cytogenetic abnormalities in acute myeloid leukaemia and myelodysplastic syndromes
}

\author{
GEORGINE E. DE GREEF \\ ANNE HAGEMEIJER
}

Acquired chromosomal changes are a characteristic of all tumour cells. In this chapter we shall briefly review the cytogenetic abnormalities that are more specifically associated with acute myeloid leukaemia (AML) and the myelodysplastic syndromes (MDS). Their clinical usefulness and their significance for the understanding of the mechanism of leukaemogenesis will be discussed.

Mitotic abnormalities had already been discovered in tumour cells by the end of the last century (Arnold, 1879). Boveri (1914) was the first to suggest the existence of a relationship between the abnormal chromosome pattern and the malignant phenotype of the cells. Nowell and Hungerford (1960) reported the constant presence of a small marker chromosome, known as the Philadelphia chromosome, in patients with chronic myeloid leukaemia (CML). With the use of banding techniques (Caspersson et al, 1970; Hagemeijer et al, 1979) recurrent patterns of numerical or structural chromosome abnormalities were found to correlate with distinct haematological malignancies.

At several International Workshops on Chromosomes in Leukaemia, defined correlations were found between cytogenetic abnormalities, morphology and immunophenotype, clinical, epidemiological and aetiological factors, as well as prognostic implications for therapeutic response and survival. The development of molecular genetics in the 1980s led to the characterization of the genes involved in the cytogenetic abnormalities. These studies revealed a new mechanism of oncogenesis by illegitimate gene fusion, as a consequence of translocation. Information was, and still is, obtained on the different molecular mechanisms and changes leading to malignant transformation. In addition, these analyses provide insight into the genetic control of normal haematopoiesis. 


\section{CHROMOSOME AND MOLECULAR CHANGES IN AML AND MDS}

\section{Cytogenetic findings and clinical significance}

Chromosomal changes can be detected in the majority of cases of acute myeloid leukaemia or myelodysplastic syndromes. These changes in karyotype are clonal and an intrinsic feature of leukaemia. With response to treatment the malignant clone may disappear, but in case of relapse the leukaemic cells generally carry the original clonal abnormalities, sometimes with additional changes.

Chromosomal abnormalities can be divided into different categories:

1. Recurrent structural abnormalities, such as balanced reciprocal translocations, inversions and insertions. No gain or loss of chromosome material is found, the conserved breakpoints are specific and have often clinical relevance. For instance, adult patients with AML carrying the translocation $\mathrm{t}(8 ; 21), \mathrm{t}(15 ; 17)$ or inversion inv(16) are associated with AML FAB M2,M3 and M4eo respectively and known to have a better prognosis (Marosi et al, 1992; Swansbury et al, 1994).

2. Unbalanced aberrations, which include gain or loss of chromosome material and, therefore, of genetic material. The breakpoints vary from patient to patient. The changes are primary or secondary; they are relatively easy to detect and have been associated with various clinical entities.

The distribution of karyotypes may vary among different age groups. In AML, in children and young adults, there is a predominance of balanced translocations (Table 1a). In the aged or in secondary leukaemia, or MDS arising in patients with a history of toxic exposure, there is a predominance of numerical and unbalanced abnormalities, in particular a loss or deletion of chromosome number $5(5 q-,-5)$ or \#7 (7q-,-7) (Table 1b). Trisomy 8 , in contrast, as a sole or secondary change, is the most frequent abnormality in myeloid disorders. Complex karyotypes (more than three aberrations) are particularly ominous in all age groups. The specific implications of each abnormality for clinical response to therapy will be dealt with below.

\section{Gene re-arrangements in AML and MDS}

Molecular analysis of a number of recurrent translocations and the inv(16) showed involvement of the genes mapping at or very close to the chromosomal breakpoints. Both genes, one on each of the involved chromosomes, are interrupted and recombined 'in frame' to give rise to a new hybrid gene. The latter is situated on the major or constant recombinant chromosome and encodes a new fusion protein. This has been shown to be a major step in the chain of events leading to malignancy. Expression of a reciprocal product from the second derivative chromosome is sometimes observed. These newly formed oncoproteins are expressed in leukaemic cells, and for some, their oncogenic potential has been demonstrated in animal studies. A 


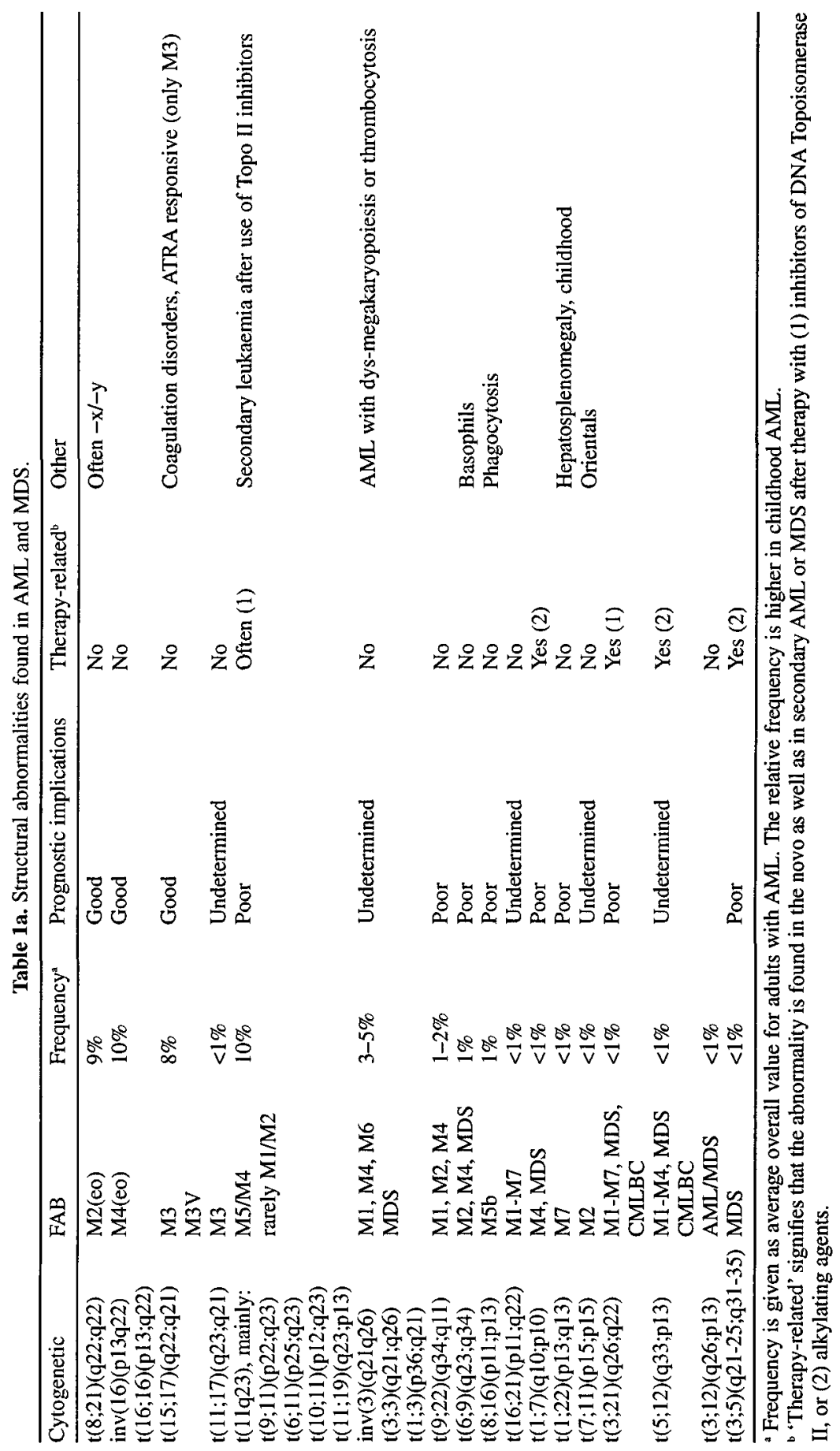




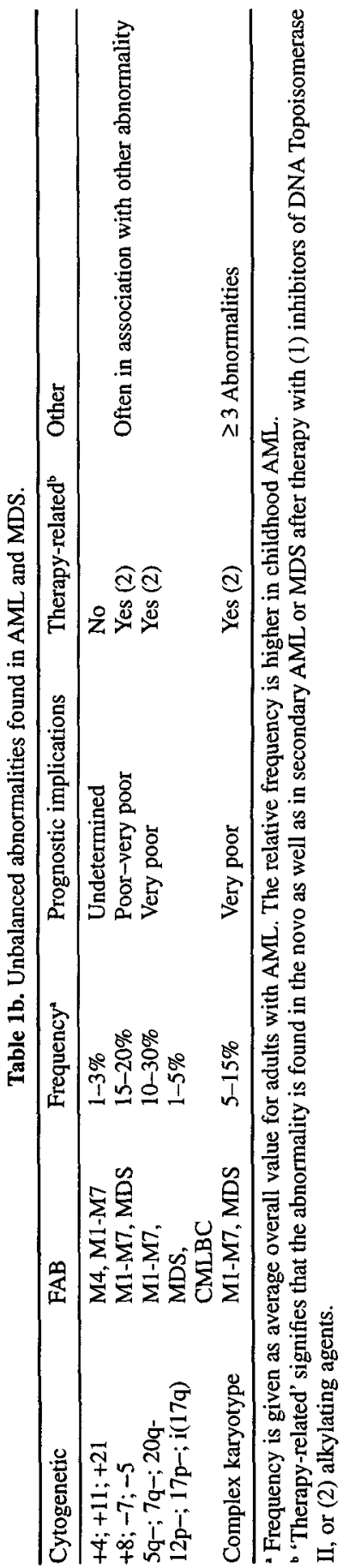


number of translocations and their fusion transcripts are now defined, and several mechanisms by which they might play a role in leukaemic transformation are suggested (Table 2).

Table 2. Molecular genetic re-arrangements caused by chromosomal translocations.

\begin{tabular}{|c|c|c|c|}
\hline Cytogenetic & Involved genes & Fusion gene product & Putative transforming mechanism \\
\hline $\mathrm{t}(8 ; 21)(\mathrm{q} 22 ; \mathrm{q} 22)$ & $\begin{array}{l}\text { ETO (CDR, MTG8); } \\
\text { AMLI }\end{array}$ & $\begin{array}{l}\text { AML1-ETO (CDR, } \\
\text { MTG8) }\end{array}$ & Suppressor myeloid differentiation \\
\hline $\operatorname{inv}(16)(\mathrm{p} 13 ; \mathrm{q} 13)$ & MYHII: CBFB & CBFB-MYH1I & Effects differentiation? \\
\hline$t(16 ; 16)$ & $M Y H 11 ; C B F B$ & & \\
\hline $\mathrm{t}(15 ; 17)(\mathrm{q} 22 ; \mathrm{q} 21)$ & $P M L ; R A R A$ & $\begin{array}{l}\text { PML-RARA }(100 \%) \\
\text { RARA-PML }(70 \%)\end{array}$ & $\begin{array}{l}\text { Dominant inhibition of } \\
\text { promyelocytic differentiation }\end{array}$ \\
\hline $\mathrm{t}(11 ; 17)(\mathrm{q} 23 ; \mathrm{q} 21)$ & $P L Z F ; R A R A$ & PLZF-RARA & \\
\hline $\mathrm{t}(9 ; 11)(\mathrm{p} 22 ; \mathrm{q} 23)$ & $A F 9 ; M L L$ & MLL-AF9 & Regulator of transcription effect on \\
\hline $\mathrm{t}(6 ; 11)(\mathrm{p} 25 ; \mathrm{q} 23)$ & $A F 6 ; M L L$ & MLL-AF6 & early differentiation \\
\hline $\mathrm{t}(10 ; 11)(\mathrm{p} 12 ; \mathrm{p} 23)$ & $A F 10 ; M L L$ & MLL-AFI0 & \\
\hline $\mathrm{t}(11 ; 19)(\mathrm{q} 23 ; \mathrm{p} 13)$ & $M L L ; E L L$ & MLL-ELL & \\
\hline$t(11 q 23)$ & $M L L$; other gene & MLL- other & \\
\hline $\mathrm{t}(9 ; 22)(\mathrm{q} 34 ; \mathrm{q} 11)$ & $A B L ; B C R$ & BCR-ABL & Tyrosine kinase activation \\
\hline $\mathrm{t}(6 ; 9)(\mathrm{q} 23 ; \mathrm{q} 34)$ & $D E K ; C A N$ & DEK-CAN & \\
\hline $\mathrm{t}(16 ; 21)(\mathrm{p} 11 ; \mathrm{q} 22)$ & $F U S(T L S) ; E R G$ & FUS-ERG & \\
\hline \multirow[t]{3}{*}{$\mathrm{t}(3 ; 21)(\mathrm{q} 26 ; \mathrm{q} 22)$} & $E V I-1 ; A M L I$ & AML1-EVI-1 & Lack of transcriptional activity \\
\hline & $E A P ; A M L I$ & AML1-EAP & Repressor gene? \\
\hline & $M D S 1 ; A M L 1$ & AML1-MDSI & \\
\hline $\mathrm{t}(5 ; 12)(\mathrm{q} 33 ; \mathrm{p} 13)$ & $P D G F R B ; T E L$ & TEL-PDGFRB & \\
\hline$t(3 ; 12)(q 26 ; p 13)$ & unknown; $T E L$ & & \\
\hline
\end{tabular}

Originally, gene fusion in AML was thought to be a highly specific property of exclusive partners. More recently, genes have been identified that may recombine with a variety of other genes; this gives rise to different translocations and to leukaemias which can be of different phenotype or lineage. For example, the $M L L$ gene on 11q23 and the TEL gene on 12p13 may be involved in AML, MDS as well as acute lymphoblastic leukaemia (ALL).

Numerical changes and deletions result in gene unbalance. The loss of genetic material is suggestive for another mechanism of leukaemogenesis by loss of tumour suppression. Such tumour suppressor genes have been shown to play a role in familial solid tumours. Many studies currently concentrate on the definition of such genes on $5 q, 7 q, 20 q$ and other chromosomal regions that are frequently lost in AML and MDS.

\section{Methods of detection}

Genetic abnormalities of leukaemic cells can be investigated using a number of different techniques: karyotype analysis with banding techniques, fluorescence in situ hybridization (FISH), Southern blotting, reverse transcriptase polymerase chain reaction (RT-PCR) and immunological 
detection of a specific oncoprotein. The latter two methods assay for the RNA and protein product of the oncogene.

To obtain cells at the metaphase stage, short-term cultures with or without the use of growth factors or mitogens are applied. Banding techniques induce differential staining along the chromosomes, allowing identification of each chromosome by microscopy or on photographs. This approach reveals a complete picture of the genetic changes at the chromosomal level, i.e. both numerical and structural. It also provides information on the complexity of the clonal abnormalities. Sometimes it may also disclose the presence of more than one neoplastic cell population. One of the major disadvantages is the limited resolution of banding. On average, a chromosome band contains from 3 to $5 \times 10^{6}$ DNA base pairs of DNA and may contain up to 100 genes. A deletion of part of a band may be submicroscopic and therefore not detectable.

FISH is based on the property of single-stranded DNA to hybridize specifically with complementary sequences. DNA probes, specific for a chromosome or a given gene, are labelled with non-isotopic haptens such as biotin or digoxigenin (Pinkel et al, 1988). FISH bridges the gap in resolution between conventional cytogenetics and molecular DNA techniques and is becoming more and more sensitive. Larger probes can be used on interphase cells, overcoming the necessity to obtain metaphases and obviating the possible selection that may occur in culture. Interphase molecular cytogenetics allows for the screening of large numbers of cells and hence is ideal for follow-up studies of patients and for the detection of minimal disease.

The most interesting feature of FISH is the possibility of combining it with other identification techniques like cytomorphology or immunophenotyping (van Lom et al, 1993). Using these approaches, specific genetic defects can be assigned to well defined subpopulations of cells and reciprocally selective subgroups of cells can be screened for genetic changes.

The chromosomal breakpoints of specific translocations are generally clustered in one or a few of the introns of the involved genes. These breakpoint clusters can be probed, and Southern blotting is a major tool for diagnosing re-arrangement of those genes-such as the MLL gene-which have multiple possible targets.

The RT-PCR technique amplifies the specific 'fusion transcript' that is characteristic of a translocation. RT-PCR, in theory, has the power to detect one leukaemic cell among $10^{6}$ cells, but is also extremely sensitive to laboratory contamination.

The advantage of the molecular analysis is its high sensitivity and resolution. The limitation is that only one question at a time can be answered. Molecular techniques are used now to evaluate response to therapy and measure residual disease in remission samples or forecast relapse, or to determine residual leukaemia in autologous haematopoietic stem-cell transplants. The same methods are employed to assess donor chimerism after allogeneic bone marrow transplantation. They are also very convenient to screen particular categories of patient for frequent 
aberrations with significant prognostic implications (e.g. screening of leukaemia for the $11 \mathrm{q} 23$ translocation).

\section{SPECIFIC ABNORMALITIES IN AML}

In this chapter we will deal with the most frequent and clinically most significant chromosomal abnormalities. An overview of all translocations, the involved genes and their fusion products is given in Tables 1 and 2 .

\section{$t(8 ; 21)(q 22 ; q 22)$}

This is the most frequent translocation apparent in about $10 \%$ of adult patients and $20 \%$ of children with AML. It is associated with the AML FAB M2, and shows a specific morphology. Typical morphological features of $t(8 ; 21)$ AML include eosinophilia, prominent Auer rods, salmon-coloured granulae, large cytoplasmic globules and vacuoles. The immunological markers CD19 and, less often, CD56, may be present. Loss of a sex chromosome may occur, as well as an interstitial deletion of the long arm of chromosome $9 \operatorname{del}(9)(q 13 q 32)$. Both abnormalities are indicative of clonal progression. Finally, complex variants of $t(8 ; 21)$ have been described. Clinically, AML with $t(8 ; 21)$ is associated with a relatively good prognosis with regard to complete remission $(80 \%)$ and disease-free survival (67\%) probabilities (Marosi et al, 1992; Dastugue et al, 1995). Although relapses do occur in these patients (Fenaux et al, 1989), reinduction of remission is often successful, unless secondary abnormalities occur (Garson et al, 1989).

In $t(8 ; 21)$ part of the long arm of chromosome 8 is reciprocally translocated to the long arm of chromosome 21. On chromosome 21 the AML1 gene is involved (Myoshi et al, 1991), whereas on chromosome 8 it is the ETO gene (also called $C D R, M T G 8$ ). This gene encodes a nuclear protein which normally is not expressed in haematopoietic tissue. The translocation results in the formation of the $A M L 1-E T O / C D R / M T G 8$ chimeric fusion gene on the derivative chromosome 8 , whose transcript can be detected with the use of an RT-PCR (Nisson et al, 1992; Erickson et al, 1992; Myoshi et al, 1993).

$A M L 1$ is a highly conserved gene related to the Drosophila pair-rule gene runt encoding a nuclear protein (Erickson et al, 1992; Daga et al, 1992). $A M L 1$ is the human counterpart of the murine gene for the alpha subunit of the nuclear binding protein (PEPB2) (Bae et al, 1993) also known as the core-binding factor (CBF) (Wang and Speck, 1992; Wang et al, 1993). PEBP2/CBF is a protein which is able to bind to the enhancers of T-cell specific genes and to the conserved core site of the mammalian-type retroviral enhancers. Due to alternative splicing, AML-1 comes in various lengths. The normal AMLI gene (full-length form) acts as a transcriptional activator reporter gene for CBF, GMCSF CSF1R and TCRB sites (reviewed by Nucifora and Rowley, 1995). It is suggested that the shorter form of the $A M L 1$ gene, AML1a, which still contains the runt domain, can act as a suppressor of the reporter gene. Recently, it was found that a larger, 
alternative spliced form of the $A M L 1$ gene, called AML1b, is capable of inducing the transcription of a reporter gene. The $t(8 ; 21)$ fusion protein (maintaining the runt homology) appeared to block this transactivation by AML1b (Meyers et al, 1995). This can result in suppression of the normal, myeloid differentiation in cells carrying the $t(8 ; 21)$ (Nuchprayoon et al, 1991). The breakpoints in the $A M L I$ gene are clustered between exons 5 and 6 (Myoshi et al, 1991), and result in the formation of a constant size fusion transcript regardless of their exact position within the rather large intron (de Greef et al, 1995).

Recently several groups have found that the fusion transcript of AML1ETO persists in patients in long remission (Nucifora et al, 1993a; Kusec et al, 1994). This finding would suggest that the presence of cells with the $t(8 ; 21)$ in itself does not indicate the presence of residual leukaemic cells or impending relapse, but a quantitative PCR-test should be developed.

\section{$\mathrm{t}(3 ; 21)(\mathrm{q} 26.2 ; \mathrm{q} 22)$}

The $A M L 1$ gene is also known to be involved in $\mathrm{t}(3 ; 21)(\mathrm{q} 26 ; \mathrm{q} 22)$. This translocation is far less frequent than $\mathrm{t}(8 ; 21)$. It is associated not only with (therapy-related) AML but also with MDS and blast crisis of CML. On chromosome 21 the breakpoints in the $A M L 1$ gene are more heterogeneous in comparison to $t(8 ; 21)$ and occur after either exon 5 or exon 6 (Sacchi et al, 1994). On chromosome 3q26 the EAP gene (Nucifora et al, 1993b), the EVI-1 gene (Mitani et al, 1994) and a gene called MDS1 (Nucifora et al, 1994) have been identified. Chimeric fusions between the $A M L 1$ gene and the EAP, EVI-1 or MDS1 gene have recently been detected by RT-PCR in patients with $\mathrm{t}(3 ; 21)$ (reviewed by Nucifora and Rowley, 1995). The EAP gene is recognized now as the ribosomal protein L.22 and belongs to a family of pseudogenes (Toczyski et al, 1993). In a number of patients with $\mathrm{t}(3 ; 21)$ the chimeric fusion protein AML-1/EAP did not contain amino acid homology with normal EAP. Therefore, the transcript might lack its transactivational activity and act as a repressor for the $A M L 1$ gene (Nucifora et al, 1993b; Sacchi et al, 1994).

The EVI-1 gene can also be found at 3q26 more downstream of the EAP and MDS1 genes. It encodes a DNA binding protein and contains two domains of zinc finger motifs as well as an acidic domain (Delwel et al, 1993). The EVI-I gene is expressed in $30 \%$ of patients with AML, MDS or CML-blast crisis (CMLBC), without evidence of 3q26 abnormalities (Russel et al, 1994). Moreover, it is expressed in leukaemias and MDS which carry less frequent $3 \mathrm{q} 26$ abnormalities such as $\mathrm{t}(3 ; 3)(\mathrm{q} 21 ; \mathrm{q} 26)$ or ins(3;3)(q21q25q26). In AML t(3;3)(q21;q26) as well as inv(3)(q21q26) is associated with disturbances in thrombopoiesis and megakaryocyte development and is often accompanied by other complex cytogenetic abnormalities (Fonatsch et al, 1994). The entire EVI-I protein is conserved in the chimeric transcript resulting from the $t(3 ; 21)$ and expressed in the leukaemic cells. Its exact role in the development of leukaemia has not been established yet but it might block stem cell differentiation (Matsugi et al, 1995). 


\section{$t(15 ; 17)(q 22 ; q 21)$}

The $t(15 ; 17)$ is clinically associated with acute promyelocytic leukaemia (APL), FAB M3, or its microgranular variant M3V, where it is found in $95 \%$ of the cases. This leukaemia is characterized by a clonal expansion of haematopoietic progenitor cells, blocked at the promyelocyte stage of differentiation (Rowley et al, 1977). Clinically it is associated with prominent diffuse intravascular coagulation. APL has a relatively good prognosis, and shows the unique property to respond to treatment with high-dose all-trans retinoic acid (ATRA), a vitamin A derivative (Huang et al, 1988). The reciprocal translocation results in the fusion of the $P M L$ gene on chromosome $15 \mathrm{q} 22$ to the retinoid acid receptor alpha $R A R A$ located on chromosome $17 \mathrm{q} 21$. The fusion product 5'-PML-RARA-3', encoded by the der(15), is expressed in all cases. The reciprocal fusion product RARAPML, encoded by the der(17), is detected in $70 \%$ of APL. PML is found to be expressed in every human cell line, although in human bone marrow it is restricted to the myeloid lineage (Daniel et al, 1993). Its expression in Hela cells was found to be highest in the G1 phase (Chang et al, 1995). The gene has nine coding exons and a proline-rich $\mathrm{N}$-terminus which resembles the transcription activation domain of some genes. In addition, three clusters of zinc fingers are found followed by an $\alpha$-helical region. Functionally, it has been suggested that the $P M L$ gene plays a role as a transcription factor (Kakizuka et al, 1991; de The et al, 1991) and is now known to belong to a new family of zinc-finger transcription factors, i.e. the so-called B-box family (Goddard et al, 1991). Based on the clinical response to treatment with ATRA, it has been suggested that disturbances of the RARA receptor gene which maps to $17 \mathrm{q} 21$ play a role in the pathogenesis of APL. A non-functional heterodimer is formed between the $P M L$ gene and the fusion protein PML-RARA (Perez et al, 1993). Recent data show that disturbance of the normal function and cellular localization of the $P M L$ gene product in the presence of PML-RARA affects normal cell growth and differentiation (Mu et al, 1994). Also, a positive PML-RARA PCR reaction in patients in clinical remission is associated with impending relapse (Fukutani et al, 1995). Reports have been made of rare cytogenetic variants and masked translocations that involve PML and RARA as well. Even more rare are two other translocations associated with AML-M3: the $\mathrm{t}(11 ; 17)(\mathrm{q} 23 ; \mathrm{q} 21)$ that re-arranges the PLZF gene with RARA (Chen et al, 1994), and a single report of a $t(5 ; 17)$. So the exact roles of both involved genes and their fusion proteins in the pathogenesis of APL still remain to be established.

\section{inv(16)(p13q22) and $t(16 ; 16)(p 13 ; q 22)$}

The inv(16)(p13q22) and $t(16 ; 16)$ are also seen at comparatively high frequency in de novo AML and account for about $16 \%$ of cytogenetic abnormalities in these patients. A strong association is apparent between chromosome 16 abnormalities and AML FAB M4Eo, but they have also been found in AML M2, M4 without eosinophilia, M5, MDS and CML 
blast crisis (Campbell et al, 1991). Patients usually have a good prognosis (almost $100 \%$ of CR), but (leptomeningeal) relapses have been reported (Holmes et al, 1985). For these reasons, detection of this subtle chromosomal re-arrangement is rather important. Probes for FISH analysis are useful to support the diagnosis by conventional cytogenetics.

On 16p13 the smooth muscle myosin heavy chain gene is involved (MYHII) (Liu et al, 1993a; van der Reijden et al, 1993). On 16q22 the involved gene has been identified as the core binding factor- $\beta$ gene ( $C B F \beta$ also known as $P E P B 2 / C B F$ ) (Liu et al, 1993b). $C B F$ is known as a heterodimeric transcription factor which has DNA binding facilities for T-cell and myeloid-specific genes. In addition to the $\beta$ unit, $C B F$ also consists of an $\alpha$ unit. The latter is coded for by the AMLl gene on chromosome 21 and is responsible for DNA interactions. The $\beta$ unit acts as stabilizer of this DNA-binding activity. The inv(16) results in an abnormal fusion gene 5-'CBFB/MYH11-3'. A single breakpoint has been identified within $C B F \beta$, whereas $M Y H 11$ may show four alternative breakpoints. The fusion product has been identified with the use of RTPCR (Liu et al, 1993a; Claxton et al, 1994). More recently breakpoint heterogeneity was demonstrated in both genes (Shurtleff et al, 1995). Recent CBF $\beta-M Y H 11$ fusion transcripts were found in a series of AML M4Eo, but also in about $10 \%$ of AML M4 cases without eosinophilic abnormalities (Poirel et al, 1995). Large follow-up series have not yet been reported. In analogy to the alternatively spliced AML1-ETO fusion transcripts, which may lead to truncated $\mathrm{CBF} \alpha$ units, alternative splicing in the CBF $\beta$ unit has also been identified (van der Reijden et al, 1995). In summary both inv(16) and $t(8 ; 21)$ are found in leukaemias with relatively good prognosis and both are associated with disturbances within the CBF transcription factor. These data may suggest a common mechanism of leukaemic transformation. The fusion proteins in combination with their alternatively spliced products may exert different effects on normal differentiation.

\section{Abnormalities involving 11q23}

The $M L L$ gene on 11q23, also called HRX, Htrx-1, ALL1 (Djabali et al, 1992; Gu et al, 1992; Tkachuk et al, 1992; Domer et al, 1993), is involved in various chromosomal abnormalities and associated with acute lymphoblastic leukaemias (ALL), primary or secondary (therapy-related) AML, mixed lineage leukaemia as well as rare cases of myelodysplasia and malignant lymphomas. The $11 \mathrm{q} 23$ abnormalities are found in more than $70 \%$ of leukaemias in infants (less than 1 year old) but they are also relatively frequent in children and adults. As the $M L L$ gene can fuse to a number of different partner genes, it plays a role in several chromosomal translocations. In ALL, $\mathrm{t}(4 ; 11)(\mathrm{q} 21 ; \mathrm{q} 23)$ is the most frequent $11 \mathrm{q} 23$ abnormality followed by $\mathrm{t}(11 ; 19)(\mathrm{q} 23 ; \mathrm{p} 13.3)$. Patients with ALL and $\mathrm{t}(4 ; 11)$ have high WBC, null cell immunophenotype, and are more often of the female sex. In children and adults with de novo AML $11 \mathrm{q} 23$ abnormalities are found in $4-6 \%$ and most frequently involve $t(9 ; 11)(\mathrm{p} 22 ; \mathrm{q} 23)$, 
$\mathrm{t}(6 ; 11)(\mathrm{q} 27 ; \mathrm{q} 23)$ and $\mathrm{t}(11 ; 19)(\mathrm{q} 23 ; \mathrm{p} 13.1)$. An association of 11q23 abnormalities with $\mathrm{FAB}$ M4/M5, high WBC, extramedullary localization, skin infiltration, female sex and poor prognosis, has been established in infants (Sorensen et al, 1994). In adults with AML M4/M5 the presence of 11q23 abnormalities may not predict poor prognosis (Bower et al, 1994). In addition, other 11q23 variants, including $\mathrm{t}(1 ; 11)(\mathrm{p} 32 ; \mathrm{q} 23), \mathrm{t}(\mathrm{X} ; 11)(\mathrm{q} 13 ; \mathrm{q} 23)$, $\mathrm{t}(10 ; 11)(\mathrm{p} 12 ; \mathrm{q} 23)$ and $\mathrm{t}(11 ; 17)(\mathrm{q} 23 ; \mathrm{q} 25)$ have been reported in AML. Although translocations are most frequently seen, deletions (del 11q) have also been demonstrated. 11q23 abnormalities are also highly prevalent in secondary leukaemia in patients previously treated with topoisomerase II inhibitors (Gill Super et al, 1993). Many of these translocations exchange chromosomal segments of similar size, and they are therefore difficult to detect in poorly banded metaphases. The prevalence of $M L L$ re-arrangement as detected by Southern can be of the order of $10 \%$ of the cases.

The $M L L$ gene on chromosome 11 covers about $100 \mathrm{~kb}$ and contains at least 21 exons. The MLL protein contains several regions that show homology to that of the Drosophila trithorax gene, which is involved in the transcriptional regulation in Drosophila embryogenesis. It also contains amino-terminal AT hooks which can bind to AT-rich regions of the minor groove of the DNA double helix (Grosschedl et al, 1994). In this way it may facilitate the action of other DNA-binding factors. The cystein-rich region (CRR), also found on the $M L L$ gene product, shows homology with mammalian DNA methyltransferase, which might discriminate between hemimethylated and ummethylated DNA. All these regions lead to the presence of at least two DNA-binding domains (TRX and four zinc-fingers) and suggest a role as a transcriptional regulator. The breakpoints in the $M L L$ gene are clustered between exons 5 and 11 of the gene between the two DNA-binding sites. At the present time eight different partner genes have been molecularly characterized. Some of these share sequence homology, such as $A F 10$ (10p12) with $A F 17$ (17q25), and $A F 9$ (9p22) with $E N L$ (19p13). However, most do not. Fusion transcripts are found between the $M L L$ and its different partner genes, coding for several chimeric proteins (for a review see Bernard and Berger (1995)). Although these chimeric proteins might influence the normal functions of the $M L L$ gene, the MLL fusion protein on the derivative chromosome 11 is expressed in all cases and is considered critical in leukaemogenesis (Rowley, 1992; Kobayashi et al, 1993; Downing et al, 1994). Several mechanisms of leukaemogenesis of MLL might be involved-such as competition for targets of normal $M L L$ or formation of a new transcription factor by fusion of AT hooks to possible transactivation domains in the product of the partner genes. As a result of the differences between most partner genes, they might contribute in different ways to leukaemogenesis. The fact that leukaemias carrying $11 \mathrm{q} 23$ abnormalities can be of myeloid, lymphoid or mixed lineage, might suggest that the critical changes occur in a very early pluripotent progenitor cell, and that the different translocations interfere with the various pathways of differentiation.

Another abnormality, also involving the $M L L$ gene, was described in AML; in this abnormality an internal tandem duplication took place within 
the gene. The partially duplicated $M L L-1$ gene is transcribed into mRNA capable of encoding a partially duplicated protein (Schichman et al, 1994). This self fusion of the gene has been reported in AML with trisomy 11, but also in AML with normal karyotype, and might be considered as another mechanism in leukaemogenesis.

\section{SPECIFIC ABNORMALITIES IN MDS}

The myelodysplastic syndromes harbour a variety of disorders which are of clonal origin. They are characterized by ineffective haematopoiesis often in combination with hypercellularity of the bone marrow. A classification can now be made according to the FAB criteria. The morphological classification already made it possible to define patients which need more intensive treatment or even an allogeneic bone marrow transplantation, as they have a poor prognosis (for instance, patients with RAEBt).

In addition to the FAB classification, the chromosomal status can be considered as a major prognostic indicator of survival, leukaemic transformation and response to treatment. Cytogenetic abnormalities are found in $32-73 \%$ of primary MDS (Second International Workshop on Chromosomes in Leukemia, 1980; Yunis et al, 1988). They consist of numerical and/or structural re-arrangements. The most frequent abnormalities found are deletion of chromosome $5(-5 / 5 q-)$, chromosome $7(-7 / 7 q-)$ and chromosome $20(20 \mathrm{q}-),-\mathrm{Y}$, or an additional chromosome $8(+8)$. Nonrandom translocations are far less frequent $(1-5 \%)$ and involve chromosomes \#3, \#6, \#9, \#16 and \#21 in the same way as can be found in patients with AML, so they will not be further discussed here. Relations have been found between the different FAB classifications and the presence of specific chromosomal abnormalities (reviewed by Heim and Mitelman, 1995). For instance, del $(5 q)$ is found in $50 \%$ of MDS type refractory anaemia (RA) and in less than $5 \%$ in chronic myelo-monocytic leukaemia (CMML). Monosomy 7 is less frequent in patients with refractory anaemia with ring sideroblasts, (RARS), whereas del(11q) and del(20q) are found more often in these patients, compared to the other MDS subgroups. In the patients with refractory anaemia with excess of blasts (RAEB) or RAEBt, the frequency of chromosomal abnormalities increases, which also may be more complex (Knapp et al, 1985; Heim and Mitelman, 1986). With respect to the prognostic significance of the chromosomal status, various studies show different outcome. The chance for leukaemic transformation has been found to be smaller in patients with an admixture of normal $(\mathrm{N})$ and abnormal (A) metaphases in comparison to patients with all abnormal (AA) metaphases (Pierre et al, 1989; Gonzalez Manzo et al, 1992). Other studies did not confirm this (Yunis et al, 1986; Billström et al, 1988). A recent study of 109 patients showed no relation between FAB and specific chromosomal abnormalities. Patients with three abnormal cell lines or complex abnormalities had the shortest survival. No statistical difference could be found in survival between NN, AN or AA patients (Parlier et al, 1994). Our own analysis of 129 patients with primary MDS also showed that overall 
survival is shortest in the presence of multiple chromosomal abnormalities in comparison to single or no chromosomal abnormality (non-published data).

Some specific abnormalities found in MDS are now known to involve gene structures which might play a role in the development of the disease. For example, mutations of the RAS oncogene and P53 gene have been reported in MDS but their exact role remains to be established.

\section{ABNORMALITIES INVOLVING CHROMOSOME 5}

\section{Deletion 5q}

The interstitial deletion of the long arm of chromosome $5\left(5 q^{-}\right)$can be found in patients with de novo and therapy-related MDS or AML. In the latter groups it can be considered as a bad prognostic sign. Within the 5qat least four different interstitial deletions can be identified, spread between $5 \mathrm{q} 13$ and $5 \mathrm{q} 35$. Of these, $5 \mathrm{q} 31$ is the segment which was found to be deleted in most patients (Pedersen and Jensen, 1991). Molecular studies have revealed the presence of several genes playing a role in proliferation and/or differentiation located on $5 \mathrm{q} 31$. These are the interleukin genes (IL-3; IL-4; IL-5; IL-9), the genes for GM-CSF; for CSF-1 receptor ( $v-F M S$ ), CD14, the zinc finger transcription factor EGR1 and the interferon response factor (IRF1). The use of FISH made it possible to analyse two distinct critical loci on $5 \mathrm{q} 31$ in patients with secondary AML and MDS. Both regions called D5S89 and EGR1 were deleted, whereas the interstitial region was conserved (reviewed by Nagarajan, 1995). The loss of the D5S89 locus involves genes that play a role in myeloid growth and differentiation and is found in RAEBt and AML with poor prognosis; it has been suggested that D5S89 is the MDS/AML tumour suppressor locus. The telomeric region near the CSFRI gene is considered as regulator of erythroid and megakaryocytic differentiation and therefore as RET locus. Further studies are essential to isolate all critical genes and to establish the consequences of their loss in patients with 5q-.

\section{$\mathbf{t}(5 ; 12)(\mathbf{q 3 3} ; \mathbf{p} 13)$}

The above translocation can be found in Ph-negative CML, chronic myeloproliferative disorders as well as in MDS-CMMOL, although it seems to be not very frequent in this group. On the molecular level, the platelet-derived growth factor receptor-B (PDGFRB) gene is involved at 5q33, with the TEL gene at 12p13 (Golub et al, 1994). The latter gene is a member of the ETS family of transcription factors. In MDS it has also been found in a variant $\mathrm{t}(10 ; 12)(\mathrm{q} 24 ; \mathrm{p} 13)$ (Wlodarska et al, 1995). Recently it has been found to form fusion transcripts also with other genes such as $A B L$ or $A M L 1$. In these cases often a loss of the other TEL allele occurs leading to a complete loss of wild-type TEL in the leukaemic cells. Deletion of TEL is found in 15\% of children with acute lymphoblastic leukaemia (Stegmaier et al, 1995). 


\section{SUMMARY}

With the use of molecular techniques it is now possible to define even subtle chromosomal abnormalities and the fusion products resulting from translocations. Defined clinical correlations can now be made and prognostic implications are already found. For instance, patients with AML carrying $\mathrm{t}(8 ; 21), \mathrm{t}(15 ; 17)$ or inv $(16)$ have a better prognosis for long-term survival. This is also illustrated by Figure 1, which shows data of the Dutch HOVON AML study. The definition of patients with a bad or good prognosis has already resulted in the adjustment of treatment protocols. In the near future, with the use of more defined molecular techniques, we might be able to characterize the chromosomal abnormality of each patient, to individualize his treatment and to recognize very early relapses.

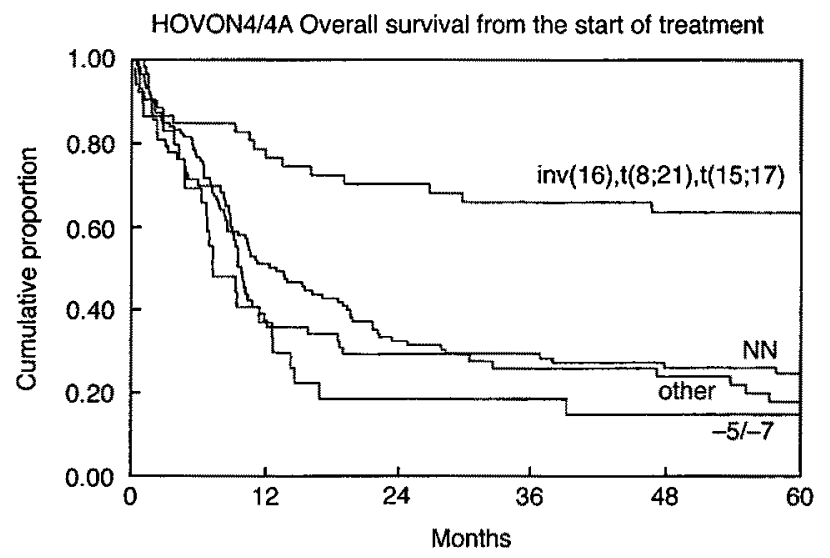

Figure 1. Overall survival in relation to cytogenetic abnormalities in 582 adult patients with AML, treated according to the HOVON 4(A) protocol.

\section{REFERENCES}

Arnold J (1879) Ueber Feinere Structur der Zellen unter Normalen und Pathologischen Bedingungen. Virchows Archiv Pathologische Anatomie Physiologie Klinische Medezin 77: 181-206.

Bae SC, Yamaguchi Y, Ogawa $E$ et al (1993) Isolation of PEPB2 $\beta$ cDNA representing the mouse homology of human acute myeloid leukemia gene, AML1. Oncogene 8: 809-814.

Bernard OA \& Berger R (1995) Molecular basis of 11q23 rearrangements in hematopoietic malignant proliferations. Genes Chromosomes and Cancer 13: 75-85.

Billström R, Thiede T, Hansen S et al (1988) Bone marrow karyotype and prognosis in primary myelodysplastic syndromes. European Journal of Haematology 41: 341-346.

Boveri T (1914) Zur Frage der Enstehung Maligner Tumoren. Jena: Verlag von Gustaf Fisher.

Bower M, Parry P, Carter M et al (1994) Prevalence and clinical correlations of $M L L$ gene rearrangements in AML-M4/5. Blood 84: 3776-3780.

Campbell LJ, Challis J, Fok T \& Garson OM (1991) Chromosome 16 abnormalities associated with myeloid malignancies. Genes Chromosomes and Cancer 3: 55-61.

Caspersson T, Zech L \& Johansson C (1970) Differential binding of alkylating fluorochromes in human chromosomes. Experimental Cell Research 60: 315-319. 
Chang K, Fan Y, Andreeff et al (1995) The PML gene encodes a phosphoprotein associated with the nuclear matrix. Blood 85: 3646-3653.

Chen Z, Guidez F, Rousselot P et al (1994) PLZF-RARA fusion proteins generated from the variant $t(11 ; 17)(q 23 ; 21)$ translocation in acute promyelocytic leukemia inhibit ligand-dependent transactivation of wild-type retinoic acid receptors. Proceedings of the National Academy of Sciences of the USA 91: 1178-1182.

Claxton DF, Liu P, Hsu HB et al (1994) Detection of fusion transcripts generated by the inversion 16 chromosome in acute myelogenous leukemia. Blood 83: 1750-1756.

Daga A, Tighe JE \& Calabi F (1992) Leukemia/Drosophila homology. Nature 356: 484.

Daniel M, Koken M, Romangné $O$ et al (1993) PML expression in hematopoietic and acute promyelocytic leukemia cells. Blood 82: 1858-1867.

Dastugue N, Payen C, Larage-Pochitalon M et al (1995) Prognostic significance of karyotype in de novo adult acute myeloid leukemia. Lenkemia 9: 1491-1498.

de Greef GE, Hagemeijer A, Morgan R et al (1995) Identical fusion transcript associated with different breakpoints in the $A M L I$ gene in simple and variant $t(8 ; 21)$ acute myeloid leukemia. Leukemia 9: 282-287.

de The H, Laveau C, Marchio A et al (199I) The PML-RARA fusion mRNA generated by the t(15;17) translocation in acute promyelocytic leukemia encodes a functionally altered RAR. Cell 66: 675-684.

Delwel R, Funabiki T, Kreider BL et al (1993) Four of the seven zinc fingers of EVI-I myeloid transforming gene are required for sequence specific binding to GA(C/T)AAGA(T/C)AAGATAA. Molecular and Cellular Biology 13: 4291-4300.

Djabali M, Selleri L, Parry P et al (1992) A trithorax-like gene is interrupted by chromosome 11q23 translocations in acute leukemias. Nature Genetics 2: 113-118.

Domer PH, Fakharzadeh SS \& Korsmeyer SJ (1993) Acute mixed lineage leukemia generates an MLLAF4 fusion product. Proceedings of the National Academy' of Sciences of the USA 90: 8538-8542.

Downing JR, Head DR, Raimondi SC et al (1994) The der(11) encoded MLL/AF-4 fusion transcript is consistently detected in $\mathrm{t}(4 ; 11)(\mathrm{q} 21 ; \mathrm{q} 23)$-containing acute lymphoblastic leukemia. Blood 83: 330-335.

Erickson P, Gao J, Chang KS et al (1992) Identification of breakpoints in $t(8 ; 21)$ acute myelogenous leukemia and isolation of fusion transcript AMLl/ETO with similarity to Drosophila segmentation gene runt. Blood 80: 1825-1831.

Fenaux P. Preudhomme C, Laï JL et al (1989) Cytogenetics and their prognostic value in de novo acute myeloid leukemia: a report on 283 cases. British Journal of Haematology 73: 61-67.

Fonatsch C, Gudat $\mathbf{H}$, Lengfelder $\mathrm{E}$ et al (1994) Correlation of cytogenetic findings with clinical features in 18 patients with inv(3)(q21;q26) or $\mathrm{t}(3 ; 3)(\mathrm{q} 21 ; \mathrm{q} 26)$. Leukemia 8: 1318-1326.

Fukutani H, Naoe T, Ohno R et al (1995) Prognostic significance of the RT-PCR assay of PML-RARA transcripts in acute promyelocytic leukemia. Leukemia 9: 588-593.

Garson OM, Hagemeijer A, Sakurai M et al (1989) Cytogenetic studies of 103 patients with acute myelogenous leukemia in relapse. Sixth International Workshop on Chromosomes in Leukemia, London, 1987. Cancer Genetics and Cytogenetics 40: 187-201.

Gill Super HJ, McCabe NR, Thirman MJ et al (1993) Rearrangements of the $M L L$ gene in therapyrelated acute myeloid leukemia in patients previously treated with agents targeting DNA-topoisomerase II. Blood 82: 3705-3711.

Goddard A, Borrow J, Freemont PS et al (1991) Characterization of a zinc finger gene disrupted by the $t(15 ; 17)$ in acute promyelocytic leukemia. Science $254: 1371-1374$.

Golub TR, Barker GF, Lovett M \& Gilliland G (1994) Fusion of PDGF receptor b to a novel ets-like gene, TEL, in chronic myelomonocytic leukemia with $\mathrm{t}(5 ; 12)$ chromosomal translocation. Cell 77: $307-316$.

Gonzalez Manzo Al, Garcia Marcilla A, Barreiro E \& Gilsanz F (1992) Cytohematologic and cytogenetic prognostic factors at diagnosis and in the evolution in 46 primary myelodysplastic syndromes. Cancer Genetics and Cytogenetics 61: 174-182.

GrosschedI R, Giesse K \& Pagel J (1994) HMG domain proteins: architectural elements in the assembly of nucleoprotein structures. Trends in Genetics 10: 94-100.

Gu Y, Nakamura T, Alder $H$ et al $(1992)$ The $t(4 ; 11)$ chromosome translocation of human acute leukemias fuses the $A L L-I$ gene, related to Drosophila trithorax, to the $A F-4$ gene. Cell 71: 701-708.

Hagemeijer A, Smit E \& Bootsma D (1979) Improved identification of chromosomes of leukemic cells in methotrexate-treated cultures. Cell Genetics 23: 208-212. 
Heim S \& Mitelman F (1986) Secondary chromosome aberrations in the acute leukemias. Cancer Genetics and Cytogenetics 22: 331-338.

Heim S \& Mitelman F (1995) Myelodysplastic syndromes. In Cancer Cyogenetics, pp 141-166. New York: Wiley-Liss.

Holmes R, Keating MJ, Cork A et al (1985) A unique pattern of central nervous system leukemia in acute myelomonocytic leukemia associated with inv(16)(p13q22). Blood 65: 1071-1078.

Huang M, Te Y, Chen S et al (1988) Use of all-trans retinoic acid in the treatment of acute promyelocytic leukemia. Blood 72: 567-571.

Kakizuka A, Miller WH, Umesono K et al (1991) Chromosomal translocation t(15;17) in human acute promyelocytic leukemia fuses $R A R A$ with a novel putative transcription factor, $P M L$. Cell 66: $663-674$.

Knapp RH, Dewald GW \& Pierre RV (1985) Cytogenetic studies in 174 consecutive patients with preleukemic or myelodysplastic syndromes. Mayo Clinic Proceedings 60: 507-516.

Kobayashi H, Espinosa RI, Thirman M et al (1993) Heterogeneity of breakpoints of 11 q23 rearrangements in hematologic malignancies identified with fluorescence in situ hybrization. Blood 82: $547-551$.

Kusec R, Laczika K, Knöbi P et al (1994) PCR detection of persisting AML1/ETO positive cells in remission blood samples of patients with $t(8 ; 21)$ acute myeloid leukemia. British Journal of Haematolgy 87 (supplement): 13 (abstr).

Liu P, Tarle SA, Hajra A et al (1993a) Fusion between transcription factor CBF $\beta / P E B P 2 \beta$ and a myosin heavy gene in acute myeloid leukemia. Science 261: 1041-1044.

Liu P, Claxton DF, Marlton P et al (1993b) Identification of yeast artificial chromosomes containing the inversion 12-p arm breakpoint associated with acute myelomonocyte leukemia. Blood 82: $716-721$.

Marosi C, Köller U, Köller-Weber E et al (1992) Prognostic impact of karyotype and immunologic phenotype in 125 adult patients with de novo AML. Cancer Genetics and Cytogenetics 61: 14-25.

Matsugi T, Kreidler BL, Delwel R \& Cleveland JL (1995) The Evi-1 zinc finger myeloid transforming protein binds to genomic fragments containing (GATA) $\sim \mathrm{n}$ sequences. Oncogene 11: 191-198.

Meyers S, Lenny N \& Hiebert SC (1995) The $t(8 ; 21)$ fusion protein interferes with AMLlb dependent transcriptional activation. Molecular and Cellular Biology 15: 1974-1982.

Mitani K, Ogawa S, Tanaka T et al (1994) Generation of the AML1-EVI-1 fusion gene in the $\mathrm{t}(3 ; 21)(\mathrm{q} 26 ; \mathrm{q} 22)$ causes blast crisis in chronic myelocytic leukemia. EMBO Journal 3: 504-510.

Miyoshi H, Shimizu K, Kozu T et al (1991) $\mathrm{t}(8 ; 21)$ breakpoints on chromosome 21 in acute myeloid leukemia are clustered within a limited region of a single gene $A M L-1$. Proceedings of the National Academy of Sciences of the USA 88: 10 431-10 434.

Miyoshi H, Kozu T, Shimizu K et al $(1993)$ The $t(8 ; 21)$ translocation results in production of an AML1-MTG8 fusion transcript. EMBO Journal 12: 2715-2721.

Mu ZM, Chin KV, Liu JH, Lozano G \& Chang KS (1994) $P M L$ a growth suppressor disrupted in acute promyelocytic leukemia. Molecular and Cellular Biology 14: 6858-6867.

Nagarajan L (1995) Molecular analysis of the 5q- chromosome. Leukemia and Lymphoma 17: 361-366.

Nisson PE, Watkins PC \& Sacchi N (1992) Transcriptionally active chimeric gene derived from the fusion of the $A M L 1$ gene and a novel gene on chromosome 8 in $t(8 ; 21)$ leukemic cells. Cancer Genetics and Cytogenetics 63: 81-88.

Nowell PC \& Hungerford DA (1960) A minute chromosome in human granulocytic leukemia. Science 132: $1497-1502$.

Nuchprayoon I, Meyers S, Scott LM et al (1994) $P E B P 2 / C B F$, the murine homolog of the human myeloid $A M L l$ and PEBP2beta/CBFbeta proto-oncoprotein, regulates the murine myeloperoxidase and neutrophil elastase genes in immature myeloid cells. Molecular and Cellular Biology 14: 5558-5568.

Nucifora G \& Rowley JD (1995) $A M L 1$ and the 8;21 and 3;21 translocations in acute and chronic myeloid leukemia. Blood 86: 1-14.

Nucifora G, Larson RET \& Rowley JD (1993a). Persistence of the $t(8 ; 21)$ translocation in patients with acute myeloid leukemia type M2 in long-term remission. Blood 82: 712-715.

Nucifora G, Begy CR, Erickson P, Drabkin HA \& Rowley JD (1993b) The 3;21 translocation in myelodysplasia results in a fusion transcript between the $A M L 1$ gene and the gene for $E A P$, a highly conserved protein associated with the Epstein-Barr virus small RNA EBER1. Proceedings of the National Academy of Sciences of the USA 90: 7784-7788. 
Nucifora G, Begy CR, Kobayashi $\mathrm{H}$ et al (1994) Consistent intergenic splicing and production of multiple transcripts between $A M L 1$ at $21 \mathrm{q} 22$ and three unrelated genes at $3 \mathrm{q} 26$ in $(3 ; 21)(\mathrm{q} 26 ; \mathrm{q} 21)$ translocation. Proceedings of the National Academy of Sciences of the USA 91: 4004-4009.

Parlier V, van Melle G, Beris Ph et al (1994) Hematologic, clinical, and cytogenetic analysis in 109 patients with primary myelodysplastic syndrome. Cancer Genetics and Cytogenetics 78: $219-231$.

Pedersen B \& Jensen IM (1991) Clinical and prognostic implications of chromosome 5q deletions 96 high resolution studied patients. Leukemia 5: 566-573.

Perez A, Kastner P, Sethi S et al (1993) Distinct DNA binding properties and heterodimeric interaction with $R X R$. EMBO Journal 12: 3171-3182.

Pierre RV, Catovski D, Mufti GJ et al (1989) Clinical-cytogenetic correlations in myelodysplasia (preleukemia). Cancer Genetics and Cytogenetics 40: 149-161.

Pinkel D, Landegent J, Collins C et al (1988) Fluorescent in situ hybridization with human chromosome-specific libraries: Detection of trisomie 21 and translocations of chromosome 4. Proceedings of the National Academy of Sciences of the USA 85: 9138-9142.

Poirel H, Radford-Weiss I, Rack K et al (1995) Detection of the chromosome 16 CBF $\beta-M Y H 11$ fusion transcript in myelomonocytic leukemias. Blood 85: 1313-1322.

Rowley JD (1992) The der(11) chromosome contains the critical breakpoint junction in the 4;11,9;11 and 11;19 translocations in acute leukemia. Genes Chromosomes and Cancer 5: 264-266.

Rowley JD, Colomb HM \& Dougherty C (1977) 15/17 translocation, a consistent chromosomal change in acute promyelocytic leukemia. Lancet i: 549-550.

Russel M, List A, Greenberg P et al (1994) Expression of $E V I-1$ in myelodysplastic syndromes and other hematologic malignancies without 3q26 translocations. Blood 84: 1243-1248.

Sacchi N, Nisson PE, Watkins PC et al (1994) AMLI fusion transcripts in $\mathrm{t}(3 ; 21)$ positive leukemia: evidence of molecular heterogeneity and usage of splicing sites frequently involved in the generation of normal AML/ transcripts. Genes Chromosomes and Cancer 4: 226-234.

Schichman SA, Caligiuri MA, Strout MP et al (1994) $A L L-I$ duplication in acute leukemia. Proceedings of the National Academy of Sciences of the USA 91: 6236-6239.

Second International Workshop on Chromosomes in Leukemia (1980) Chromosomes in preleukemia. Cancer Genetics and Cytogenetics 2: 108-113.

Shurtleff SA, Meyers S, Hiebert SW et al (1995) Heterogeneity in CBF $\beta / M Y H 11$ fusion messages encoded by the inv(16)(p13q22) and the $\mathrm{t}(16 ; 16)(\mathrm{p} 13 ; \mathrm{q} 22)$ in acute myelogenous leukemia. Blood 85: 3695-3703.

Sorensen PHB, Chen CH, Smith FO et al (1994) Molecular rearrangements of the $M L L$ gene are present in most cases of infant acute myeloid leukemia and are strongly associated with monocytic or myelomonocytic phenotypes. Journal of Clinical Investigation 93: 429-437.

Stegmaier K, Pendse S, Barker GF et al (1995) Frequent loss heterozygosity at the TEL gene locus in acute lymphoblastic leukemia of childhood. Blood 86: 38-44.

Swansbury GJ. Lawler SD, Alimena G et al (1994) Long term survival in Acute Myelogenous Leukemia: a second follow up of the Fourth International Workshop on chromosomes in leukemia. Cancer Genetics and Cytogenetics 73: $1-7$.

Tkachuk DC, Kohler S \& Cleary ML (1992) Involvement of a homolog of Drosophila-trithorax by 11 q23 chromosomal translocations in acute leukemias. Cell 71: 691-700.

Toczyski D, Matera AG, Ward DC \& Steitz JA (1993) The Epstein Barr virus (EBV) small RNA EBER1 binds and relocalizes ribosomal protein L22 in EBV-infected human B-lymphocytes. Proceedings of the National Academy of Sciences of the USA 91: 3463-3467.

van der Reijden BA, Dauwerse JG, Wessels JW et al (1993) A gene for myosin peptide is disrupted by the inv(16)(p13q22) in acute non-lymphocytic leukemia M4Eo. Blood 82: 2948-2952.

van der Reijden BA, Lombardo M, Dauwerse JG et al (1995) RT-PCR diagnosis of patients with acute nonlymphocytic leukemia and inv (16)(p13q22) and identification of new alternative splicing in CBFB-MYH11 transcripts. Blood 86: 277-282.

van Lom K, Hagemeijer A, Smit EME et al (1993) In situ hybridization on May-Grünwald Giemsastained bone marrow and blood smears of patients with hematologic disorders allows detection of cell lineage specific cytogenetic abnormalities. Blood 82: 884-888.

Wang S \& Speck NA (1992) Purification of core-binding factor, a protein that binds the conserved core site in murine leukemia virus enhancers. Molecular and Cellular Biology 12: 89-102.

Wang S, Wang Q. Crute BE et al (1993) Cloning and characterization of subunits of the T-cell receptor and murine leukemia virus enhancer core-binding factor. Molecular and Cellular Biology 13: $3324-3339$. 
Wlodarska I, Mecucci C, Marynen P et al (1995) TEL gene is involved in myelodysplastic syndromes with either the typical $t(5 ; 12)(\mathrm{q} 33 ; \mathrm{p} 13)$ translocation or its variant $t(10 ; 12)(\mathrm{q} 24 ; \mathrm{pl} 13)$. Blood 85: $2848-2852$.

Yunis JJ, Rydell RE, Oken MM et al (1986) Refined chromosome analysis as an independent prognostic indicator in de novo myelodysplastic syndromes. Blood 67: 1721-1730.

Yunis JJ, Lobell M, Arnesen MA et al (1988) Refined chromosome study helps define prognostic subgroups in most patients with primary myelodysplastic syndrome and acute myelogenous leukemia. British Journal of Haematology 68: 189-194. 